\title{
Direitos humanos da mulher: considerações acerca do desconhecimento
}

da Lei Maria da Penha

Tatiana de Carvalho Socorro', Lucas Dias Freitas², Lilianne Cruz Samuel², Ellen Karine Santos de Jesus ${ }^{2}$

\section{Resumo}

O presente estudo tem como objetivo informar à população sobre a violência doméstica contra a mulher a fim de motivar a denúncia. Como metodologia foi utilizada a pesquisa participante e a aplicação de um questionário aos 58 participantes da pesquisa - clientes e feirantes do Mercado Albano Franco, no município de Aracaju, Sergipe. Após a aplicação desse instrumento, constatou-se que esse público possuía conhecimentos sobre a temática e ciência da existência da Lei Maria da Penha, mas desconheciam o seu conteúdo. Em seguida, efetuou-se uma exposição oral no intuito de esclarecer a referida lei, fornecer informações sobre seu conteúdo e motivar a realização de denúncias. Esperase que esta pesquisa contribua para o incremento de outras investigações acerca da violência doméstica contra a mulher, colabore com a bibliografia atual sobre o tema e proporcione uma reflexão com o intuito de subsidiar projetos de melhoria da qualidade de vida da figura feminina.

\section{Palavras-chave}

Direitos Humanos. Gênero. Violência Doméstica.

1. Doutoranda em Família na Sociedade Contemporânea na Universidade Católica do Salvador; professora do Departamento de Direito da Universidade Tiradentes. E-mail: tatiucsal@gmail.com.

2. Graduandos em Direito na Universidade Tiradentes. E-mail: lucas.22f@hotmail.com; liliannecs@yahoo.com. br; ell_karine@hotmail.com. 


\title{
Human rights of women: considerations about the lack of awareness of Maria da Penha Law
}

Tatiana de Carvalho Socorro*, Lucas Dias Freitas *, Lilianne Cruz Samuel ${ }^{* *}$, Ellen Karine Santos de Jesus ${ }^{* *}$

\begin{abstract}
This study aims to inform the public about domestic violence against women to encourage them to complain. We used a participatory research methodology and applied a questionnaire to the 58 participants, which were customers and stallholders of Albano Franco Market, Aracaju, state of Sergipe. We observe that the participants were aware of the existence of the Maria da Penha Law, but unaware of its complain. Thus, we propose an oral presentation aiming enlighten, provide and encourage them to complain. This research aims to contribute to the increase of other researches about domestic violence against women, collaborate with the literature and provide reflections to support projects to improve the quality of life of women.
\end{abstract}

\section{Keywords}

Human Rights. Gender. Domestic Violence.

* PhD student in Family in Contemporary Society, Catholic University of Salvador, Bahia, Brazil; professor at Department of Law, Tiradentes University, Sergipe, Brazil. E-mail: tatiucsal@gmail.com.

** Undergraduate in Law, Tiradentes University, Sergipe, Brazil. E-mail: lucas.22f@hotmail.com; liliannecs@ yahoo.com.br; ell_karine@hotmail.com. 


\section{Introdução}

A violência doméstica contra a mulher recebe essa denominação por acontecer dentro do lar, em que existe um vínculo afetivo entre a mulher agredida e o agressor, e estar cotidianamente na esfera privada, o que dificulta a aplicação de ações eficazes pelo Poder Público a fim de sanar esse problema (OLIVEIRA, 2012).

A Lei 11.340/06 (Lei Maria da Penha) delimita, em seu Art. 5ํㅡㅇ o objeto de incidência, ao preceituar que para os efeitos desta Lei, "configura violência doméstica e familiar contra a mulher qualquer ação ou omissão baseada no gênero". Portanto, a existência de limites para a aplicação das normas contidas na referida lei não se refere a qualquer violência contra a mulher, mas, sim, àquela baseada no gênero, praticada no âmbito doméstico, familiar ou em uma relação íntima de afeto.

Nesse contexto, segundo pesquisa da Fundação Perseu Abramo, em parceria com o Sesc (Serviço Social do Comércio), a cada dois minutos, cinco mulheres são agredidas violentamente no Brasil $^{3}$. Além disso, Ribeiro e Coutinho (2011, p. 53) destacam que as "consequências desta violência se traduzem em uma série de agravos à saúde física, à saúde reprodutiva e à saúde mental das mulheres agredidas".

Desse modo, o estudo deste tema é de grande relevância social, já que é evidente a ocorrência desse fenômeno mundial. Ademais, é de vital importância para o Direito e outras áreas do conhecimento científico compreender esta problemática, em decorrência da magnitude de suas consequências, bem como da necessidade de buscar alternativas para aplicar e combater a violência de gênero no âmbito doméstico. Assim como é indispensável que os benefícios da Lei Maria da Penha sejam de conhecimento da população para que tenha o alcance desejado. Vale destacar que o termo "violência doméstica", no Brasil, engloba não somente aquela praticada contra mulheres, mas também aquela perpetrada contra crianças e adolescentes (STELKO-PEREIRA; WILLIANS, 2010). Entretanto, este estudo tem como foco a violência direcionada à figura feminina. Nesse sentido, realizou-se uma compreensão dessa problemática a partir de uma pesquisa que teve como objetivo geral informar a população acerca da violência doméstica contra a mulher como forma de violação dos direitos humanos a fim de motivar a denúncia. Especificamente, pretende-se trazer à discussão os benefícios da Lei 11.340/06, analisar as mudanças ocorridas após sua promulgação e relacionar a violação dos direitos humanos com a prática da violência de gênero.

\section{Fundamentação teórica}

\section{Violência contra a mulher no âmbito nacional}

A violência de gênero se define como aquela praticada com base na estrutura de poder construída historicamente e inerente ao poder patriarcal, no qual a mulher se encontra simbolicamente dominada pelo homem e em condição de subordinação (MOREIRA; BORIS; VENÂNCIO, 2011). Segundo a Organização das Nações Unidas (ONU) (2015), a igualdade de gênero, além de um direito humano básico,

3. A pesquisa intitulada "Mulheres brasileiras e gênero nos espaços público e privado" foi realizada em 25 estados brasileiros e entrevistou 2.365 mulheres e 1.181 homens com mais de 15 anos em agosto de 2010 . 0 resultado final, divulgado pela Agência Estado, foi obtido por meio de uma projeção média para a população total e confirma relatórios já divulgados pelas Nações Unidas, que afirmam que a violência doméstica é a que mais faz vítimas no mundo. Disponível em: < http://www.brasil.gov.br/governo/2011/02/cinco-mulheres-sao-agredidas-acada-dois-minutos-no-brasil >. Acesso em: 3 ago. 2015. 
tem em sua concretização enormes implicações socioeconômicas.

Observa-se que a violência doméstica contra a mulher constitui um tipo de violência que acontece constantemente no âmbito familiar, além disso, ela se apresenta no núcleo doméstico como consequência da subjugação do gênero feminino advindo do companheiro (OLIVEIRA, 2012).

A Constituição Federal prevê, em seu texto, o tratamento igualitário entre todos os cidadãos, sem que haja distinção de qualquer natureza ${ }^{4}$. Todavia, é sabido que, historicamente, homens e mulheres fazem parte de relações desiguais, perpetuadas dentro da sociedade, que compõem fatores que motivam a violência praticada contra a mulher, não só no ambiente familiar, como também no espaço público (BANDEIRA, 2014).

De acordo com a autora acima, na contemporaneidade, não se pode afirmar que houve uma mudança na dinâmica dessas relações. As concepções de patriarcado e a posição de dominação simbólica masculina ainda constituem aspectos das relações na esfera familiar e violam a dignidade da mulher enquanto ser humano (BANDEIRA, 2014). Nesse contexto, a violação resultante da violência doméstica e de gênero ainda existe na sociedade atual. Além disso, há décadas, ela é combatida pelo movimento feminista, pela comunidade acadêmica e também por outras organizações ${ }^{5}$.

No Brasil, grande parte das agressões às mulheres ocorre dentro da residência da agredida: $48 \%$ das mulheres agredidas declaram que a violência aconteceu em sua própria casa
(PNAD/IBGE, 2009). Segundo relatório recebido pelo Ministério da Justiça, em quase $70 \%$ dos casos, o agressor é o namorado, marido ou exmarido (BRASIL, 2010). No Estado de Sergipe, de acordo com a secretária da Secretaria Especial de Políticas para as Mulheres, Maria Teles, em nota publicada divulgada no site da Defensoria Pública de Sergipe em 20 de março de 2014, só em 2013, foram registrados cerca de 2,8 mil casos de violência contra a mulher. A secretária menciona também que:

O Departamento de Atendimento a Grupos Vulneráveis já registrou 528 Boletins de Ocorrência, sendo 203 inquéritos, o que traz à tona o problema social. São em ações como essas que muitas mulheres entram no processo de conscientização para serem encorajadas a denunciarem os seus parceiros.

O ordenamento jurídico brasileiro passou a combater efetivamente a violência de gênero e doméstica contra a mulher após a aprovação da Lei 11.340/06, fruto do engajamento dos movimentos feministas, de organizações que, há décadas, lutam pelo enfrentamento a esse tipo de violência, e principalmente da cidadã Maria da Penha Maia Fernandes, que lutou pela punição do seu agressor (CORRÊA, 2011).

Segundo a Cartilha "Lei Maria da Penha \& Direitos da Mulher", elaborada pelo Ministério Público e pela Procuradoria Federal, em 1994, Maria da Penha publicou o livro "Sobrevivi... Posso Contar", que, em 1998, serviu de instrumento para, em parceria com o CLADEM (Comitê Latino-americano e do Caribe para a Defesa dos Direitos da Mulher) e CEJIL (Centro

4. Art. 5ํ I, Constituição da República Federativa do Brasil de 1988: "[...] homens e mulheres são iguais em direitos e obrigações, nos termos desta Constituição".

5. CHAME - Centro Humanitário de Apoio à Mulher (BA); MUSA - Programa de Estudos em Gênero e Saúde (BA); Agende - Ações em Gênero, Cidadania e Desenvolvimento (DF); ANIS - Instituto de Bioética, Direitos Humanos e Gênero (DF); CEVAM - Centro de Valorização da Mulher Consuelo Nasser (GO); Musa - Mulher e Saúde Centro de Referência de Educação em Saúde da Mulher (MG); Casa da Mulher Renasce Companheira (PB); AMB - Articulação de Mulheres Brasileiras (PE); CEMINA - Comunicação, Educação e Informação em Gênero (RJ); Centro de Defesa da Vida (RJ). Disponível em: <http://wjdwdefesadamulher.blogspot.com.br/2011/02/ongs-quetrabalham-com-violencia-contra.html> Acesso em: 15 ago. 2015. 
pela Justiça e o Direito Internacional), denunciar o Brasil na Comissão Interamericana de Direitos Humanos da OEA (Organização dos Estados Americanos). Esse fato obrigou o Brasil a criar um projeto de lei que tratasse da prevenção e proteção da mulher em situação de violência doméstica e da punição do agressor, que, logo em seguida, foi aprovado por unanimidade pelo Congresso Nacional. Assim, surge a Lei 11.340/06, conhecida como "Lei Maria da Penha".

\section{A violência contra a mulher e direitos humanos}

A Declaração Universal dos Direitos dos Humanos foi aprovada em 1948 na Assembleia Geral da ONU logo após a Segunda Guerra Mundial e trouxe à política internacional a necessidade de discussão dos direitos intrínsecos ao ser humano, que são alvo de violação desde os séculos anteriores até o atual. Assim, estabelece Bastos (2011, p. 39), "transcendeu a noção genérica de soberania estatal e reconheceu a pessoa humana como sujeito de direitos universais".

Passados 50 anos, a ideia de direitos humanos sofreu modificações ao tratar de gênero, devido às diversas mobilizações, dentre elas, a luta das mulheres por meio do movimento feminista. Nas últimas décadas, o campo dos direitos humanos incorporou de forma lenta e gradativa as questões desse movimento (CARVALHO, 2011).

Em 1993, ocorreu em Viena, a Conferência Mundial de Direitos Humanos, que foi fundamental para inserção dos direitos humanos das mulheres, pois promoveu a sua visibilidade, aludindo ao processo de especificação do sujeito de direito e à justiça enquanto reconhecimento de identidades. Segundo Piovesan (2012), a mulher passou a ser vista diante das suas especificidades e de sua condição social. Assim, o processo político e as convenções em busca de direitos e igualdades no âmbito do gênero possibilitaram uma maior luta na defesa da mulher.

Importante destacar a Convenção de Belém do Pará (Convenção Interamericana para Prevenir, Punir e Erradicar a Violência Contra a Mulher, adotada pela OEA em 1994), que ampliou as considerações da Convenção de Viena, definiu a violência contra a mulher como "qualquer ato ou conduta baseada no gênero, que cause morte, dano ou sofrimento físico, sexual ou psicológico à mulher, tanto na esfera pública como na esfera privada", constituindo grave violação dos direitos humanos e que ainda impossibilita o exercício dos direitos fundamentais (PIOVESAN, 2012, p.78).

Na Conferência do Instituto Internacional de Direitos Humanos, Karel Vasak ${ }^{6}$, inspirado no lema da Revolução Francesa (liberdade, igualdade e fraternidade), propôs uma classificação dos direitos humanos em gerações. Assim, os direitos humanos de primeira geração seriam os de liberdade, compreendendo os civis, políticos e as liberdades clássicas que acompanham o ser humano desde o seu nascimento. A segunda geração consagra o direito de igualdade, que constitui os direitos econômicos, sociais e culturais. Já a terceira geração se aplica aos direitos à solidariedade, ao meio ambiente equilibrado, a uma saudável qualidade de vida, ao progresso, à paz, à autodeterminação dos povos e outros direitos difusos, condicionados à realização da condição humana. A violência doméstica é uma afronta aos direitos humanos da segunda geração. A própria Lei 11.340/06 ratifica a sua violação em seu Art. 6으, que diz: "A violência doméstica e familiar contra a mulher constitui uma das formas de violação dos direitos humanos". Nesse sentido, a preocupação da ONU

6. BARROS, S. R. de. Três gerações de direito. 2007. Disponível em: <http://www.srbarros.com.br/pt/tresgeracoes-de-direitos.cont>. Acesso em: 3 ago. 2015. 
com esse tema foi também confirmada em 25 de novembro de 2011, no Dia Internacional para Eliminação da Violência contra a Mulher, quando o secretário-geral, Ban Ki-moon7, fez um apelo:

A violência contra mulheres e meninas tem muitas formas e é generalizada em todo o mundo. Ela inclui estupro, violência doméstica, assédio no trabalho, abusos na escola, mutilação genital e a violência sexual em conflitos armados. Ela é predominantemente causada por homens. Seja em países desenvolvidos ou em desenvolvimento, a perversidade dessa violência deve chocar a todos. A violência - e, em muitos casos, a simples ameaça - é uma das barreiras mais significantes para a plena igualdade das mulheres.

Segundo Dias (2011), a violência doméstica é um problema de saúde pública que repercute na saúde física e psíquica da mulher. O impacto desse ato violento afeta desde a percepção da figura feminina sobre si mesma, refletida nos sentimentos de insegurança e impotência, e até em suas relações com outras pessoas. Além disso, estados de aflição, angústia e medo foram os mais destacados como consequências psicológicas deste tipo de violência.

\section{A legislação brasileira}

No âmbito nacional, destaca-se a Convenção sobre a Eliminação de Todas as Formas de Discriminação Contra a Mulher, realizada em 1982, na qual o Brasil foi um dos países signatários. Na época, o código civil brasileiro estabelecia o homem como o chefe da sociedade conjugal ${ }^{8}$. Anos depois, a Constituição de 1988 estabeleceu a igualdade entre homens e mulheres, assim dita: "Todos são iguais perante a lei, sem distinção de qualquer natureza" (BRASIL, 1988).

Entretanto, é evidente a importância destas convenções na luta das mulheres. Por exemplo, a Convenção Sobre os Direitos Políticos da Mulher ${ }^{9}$, que foi assinada em Nova lorque, em 31 de março de 1953, por ocasião da VII Sessão da Assembleia Geral das Nações Unidas. No Brasil, foi firmada em maio de 1953, sendo aprovada pelo Decreto Legislativo 123/55. A ratificação ocorreu somente em 13 de agosto de 1963. A promulgação adveio com o Decreto 52.476/63, do Presidente João Goulart. No preâmbulo da Convenção está disposto que:

Reconhecendo que toda pessoa tem o direito de tomar parte na direção dos assuntos públicos de seu país, seja diretamente, seja por intermédio de representantes livremente escolhidos, ter acesso em condições de igualdade às funções públicas de seu país e desejando conceder a homens e mulheres igualdade no gozo e exercício dos direitos políticos, de conformidade com a Carta das Nações Unidas e com as disposições da Declaração Universal dos Direitos do Homem.

Os atos, tratados, convenções ou pactos internacionais devidamente aprovados pelo Legislativo e promulgados pelo Presidente da República - inclusive quando preveem normas sobre direitos fundamentais - ingressam no ordenamento jurídico como leis, incorporando-

7. Ban Ki-moon. Mensagem do Secretário-Geral das Nações Unidas para o Dia Internacional para a Eliminação da Violência contra a Mulher. ONU, Comunicados, 25/11/2011. Disponível em: <http://www.onu.org.br/diainternacional-para-a-eliminacao-da-violencia-contra-a-mulher-2011/>. Acesso em: 16 ago. 2015.

8. Sociedade formada pelos cônjuges casados sob o regime da comunhão universal de bens, o que se justificava a luz do papel que possuía a mulher na administração dos bens resultantes da comunhão matrimonial. A esposa era submetida à tutela do marido, que era o gestor da sociedade conjugal e detinha a administração exclusiva dos bens que a compunham (GOULART; QUIRINO, 2013).

9. BRASIL. Decreto 52.476/1963. Brasília, DF: Presidência da República, 1963. Convenção sobre os Direitos Políticos da Mulher. Disponível em: < http://www2.camara.leg.br/legin/fed/decret/1960-1969/decreto-52476-12setembro-1963-392489-norma-pe.html> Acesso em: 14 ago. 2015. 
se ao sistema jurídico infraconstitucional ${ }^{10}$. Nesse contexto, cabe a interação entre ato do Poder Executivo e do Poder Legislativo, para aprovar os tratados e atos internacionais mediante a edição de decreto legislativo, que dispensa sanção ou promulgação do Presidente da Republica, visto que a Constituição Federal não possui nenhuma regra expressa que recepcione automaticamente um tratado internacional ao direito interno. Após a aprovação do tratado pelo Congresso Nacional, autoriza o Presidente da República em ratificá-lo por meio de decreto. Promulgado o decreto internacional, a norma inserida, nesse momento, adquire executoriedade interna ${ }^{11}$.

Em referência aos tratados e convenções internacionais que versam sobre direitos humanos se tornarem emendas constitucionais, é necessário que estas sejam aprovadas mediante três quintos dos votos, em dois turnos, em cada uma das Casas do Congresso Nacional. Relacionando-as a convenções e tratados internacionais que versam sobre direitos humanos, o Congresso Nacional pode incorporá-las com status de Lei Ordinária (CF, Art. 49, I) ou com status constitucional (CF, Art. 5으, § 3.ํ), a depender do quórum da aprovação. Portanto, a Lei Maria da Penha tem natureza constitucional, assegurada a nível internacional e ratificada pelo Brasil por meio de tratados sobre direitos humanos.

A lei supracitada estabelece que todo o caso de violência doméstica e intrafamiliar é crime. Após a denúncia, a agredida pode se retratar e desistir de prosseguir com o processo. Até esse momento, existe a possibilidade de retratação que conduz à extinção da punibilidade. O desencadeamento do inquérito policial depende da representação da vítima, após realizado o inquérito remetido ao Ministério Público para o oferecimento da denúncia. Esses crimes são julgados nos Juizados Especializados de Violência Doméstica Contra a Mulher, criados a partir daquela legislação, ou, nas cidades em que esses órgãos ainda não existem, nas Varas Criminais. Essa lei também tipifica as situações de violência doméstica, proíbe a aplicação de penas pecuniárias aos agressores, amplia a pena de um para até três anos de prisão e determina o encaminhamento das mulheres em situação de violência, assim como de seus dependentes, a programas e serviços de proteção e de assistência social ${ }^{12}$.

\section{Metodologia}

Para atingir os objetivos propostos, utilizou-se como estratégia metodológica a pesquisa participante, em que o ponto de origem deve estar situado em uma perspectiva da realidade social, tomada como uma totalidade em sua estrutura e em sua dinâmica, que utiliza técnicas como entrevistas, interação dos pesquisadores nos processos e em trabalhos de campo contínuos (BRANDÃO; BORGES, 2007), como uma apropriada opção para investigar acerca dos desconhecimentos do público-alvo sobre a Lei Maria da Penha.

A presente pesquisa foi realizada no Mercado Municipal Albano Franco, em Aracaju-SE, que tem como principal atração, as feiras livres que se destacam pela diversidade de produtos. Determinou-se esse local como cenário da pesquisa por ser de fácil acesso a todos os usuários, possibilitando um intenso fluxo de pessoas que frequentam. Esse público se insere em diversos níveis socioeconômicos,

10. $\mathrm{CF}$, art. $5^{\circ}, \S 2^{\circ}$ Os direitos e garantias expressos nesta Constituição não excluem outros decorrentes do regime e dos princípios por ela adotados, ou dos tratados internacionais em que a República Federativa do Brasil seja parte

11. MORAES, A. de. Direito constitucional. São Paulo: Atlas, 2010.

12. DIAS, M. B. A Lei Maria da Penha na justiça: a efetividade da Lei $11.340 / 2006$. 3. ed. São Paulo: Revista dos Tribunais, 2012. 
e acredita-se que as pessoas que possuem baixo nível de escolaridade têm menos acesso a informações relacionadas ao tema proposto.

Desse modo, participaram dessa investigação 58 pessoas (13 homens e 45 mulheres), pertencentes a diferentes classes socioeconômicas e níveis de escolaridade. Essas pessoas responderam a uma entrevista composta por cinco questões, as quais contemplavam a temática do presente estudo, com uma opção de resposta dentre duas alternativas (SIM ou $\mathrm{NÃO}$ ) oferecidas.

Em relação aos critérios de inclusão, os participantes deveriam ser maiores de 18 anos, ter disponibilidade para participar de entrevista individual e concordar em participar da pesquisa após leitura e assinatura do Termo de Consentimento Livre e Esclarecido (TCLE). Desse modo, quanto ao procedimento de coleta, inicialmente, os participantes foram abordados e esclarecidos quanto aos objetivos do estudo e, em seguida, foi solicitada sua colaboração. Após seu consentimento, eles assinaram o TCLE.

Posteriormente à aplicação da entrevista, constatou-se que os participantes possuíam conhecimentos sobre a lei Maria da Penha, tais como: suas medidas protetivas de urgência; se consideram essa lei como uma forma de prevenir a violência contra a mulher; se sabem como proceder, caso almejem realizar uma denúncia de violência doméstica contra a mulher. Em seguida, efetuou-se uma exposição oral, objetivando esclarecer esse público-alvo. Por fim, disponibilizou-se um folder explicativo com informações a respeito do tema.

Desse modo, o presente trabalho cumpriu a seguinte estruturação de uma pesquisaparticipante: (1) montagem institucional e metodológica; (2) estudo preliminar e provisório da região e da população pesquisadas; (3) análise crítica dos problemas; e (4) programação e aplicação de um plano de ação ${ }^{13}$.

\section{Resultados e discussão}

Conforme mencionado anteriormente, para a presente pesquisa foram entrevistadas 58 pessoas (13 homens e 45 mulheres), pertencentes a diferentes classes socioeconômicas e níveis de escolaridade. Oinstrumentoutilizadocompunhase de cinco perguntas, referentes ao tema da pesquisa, com uma opção de resposta dentre duas alternativas oferecidas. Seguem abaixo os dados obtidos a partir das entrevistas realizadas.

1a PERGUNTA: Você conhece a Lei Maria da Penha?

RESPOSTA: Sim: 56 (96,6\%) / Não: 02 (3,4\%)

2a PERGUNTA: Você considera que a Lei Maria da Penha seja uma forma de prevenir a violência contra a mulher?

RESPOSTA: Sim: 43 (74,1\%) / Não: 15 (25,9\%)

3a PERGUNTA: Você sabe quais são as medidas protetivas previstas na Lei Maria da Penha:

RESPOSTA: Sim: 26 (44,8\%) / Não: 32 (55,2\%)

4a PERGUNTA: Você acredita que a Lei Maria da Penha seja eficaz contra a violência à mulher?

RESPOSTA: Sim: 37 (63,8\%) / Não: 21 (36,2\%)

5a PERGUNTA: Você sabe como denunciar a violência contra a mulher?

RESPOSTA: Sim: 42 (72,4\%) / Não: 16 $(27,6 \%)$

13. GIL, A. C. Como elaborar projetos de pesquisa. São Paulo: Atlas, 2002. 
Gráfico 1 - Percentual das respostas relativas às perguntas feitas durante o questionário aplicado no Mercado Municipal Albano Franco, sobre a Lei Maria da Penha, Aracaju, 2015.

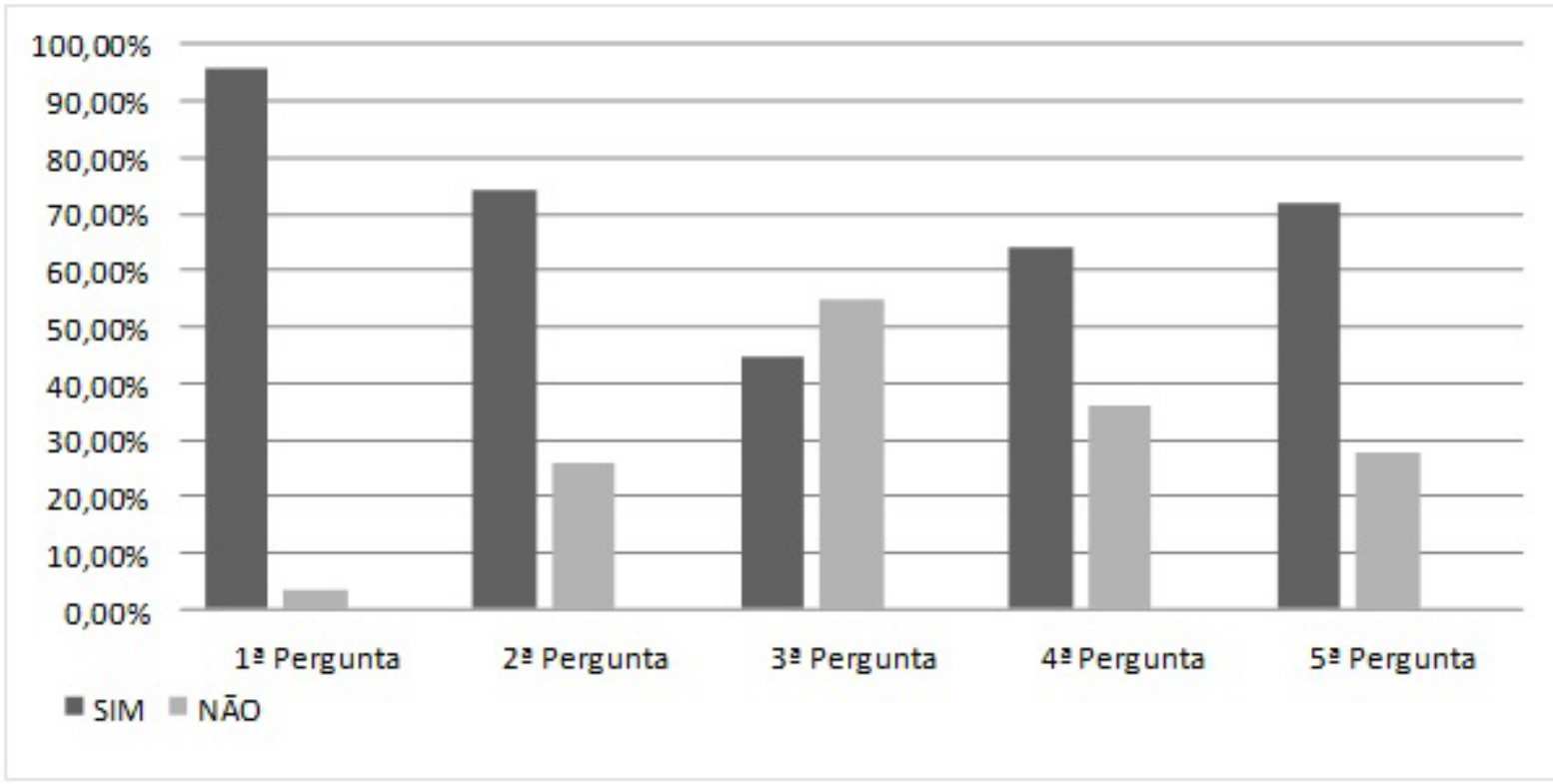

A partir dos resultados obtidos, analisamos alguns aspectos referentes ao tema proposto. A primeira pergunta do questionário, que trata da informação sobre a Lei Maria da Penha ("Você conhece a Lei Maria da Penha?"), gerou um percentual significativo no sentido afirmativo (96,6\%), evidenciando que os participantes possuíam informações acerca da existência dessa lei. Esse achado pode ser explicado devido à polêmica gerada durante o ano de promulgação da lei, em que a mídia deu maior destaque ao tema e ao projeto de lei que foi aprovado. Aos participantes que responderam negativamente, foram entregues os fôlderes, e em seguida realizou-se uma exposição oral a fim de informar em que consiste a Lei Maria da Penha e quais benefícios ela assegura.

Entretanto, grande parte das pessoas que responderam ao questionário não possuíam informações detalhadas a respeito da legislação que trata especificamente sobre a violência contra a mulher, o que pode ser comprovado na terceira pergunta do questionário ("Você sabe quais são as medidas protetivas previstas na Lei
Maria da Penha?"), que 55,2\% responderam negativamente. Nesse sentido, visualizamos a relevância da presente pesquisa participante, em que buscamos diminuir essa desinformação a partir da participação, tanto do pesquisador no contexto, grupo ou cultura que está a estudar, quanto dos sujeitos que estão envolvidos no processo da pesquisa. Além disso, a partir dos fôlderes disponibilizados, os participantes tiveram acesso a informações sobre medidas protetivas de urgência previstas pela referida lei, a exemplo do Art. 22, II, que determina o afastamento do agressor do lar, domicílio ou local de convivência com a ofendida. É importante mencionar que grande parte dos participantes da pesquisa trabalha no Mercado Municipal Albano Franco, ou seja, são feirantes; e, por este motivo, acredita-se que a quantidade de informações que os mesmos detêm, referentes ao ordenamento jurídico, é mínima. Alia-se a isso, o fato de integrarem classes sociais de baixo poder aquisitivo, em que estes trabalhadores passam a maior parte do tempo nesta feira livre, onde são escassos 
os meios de acesso a este tipo de informação.

Em relação aos aspectos da Lei Maria da Penha, ela contempla três vias de atuação: prevenção, proteção e punição (PASINATO, 2010), que são percebidas pela sociedade de forma diferente. Todavia, foi a última atuação que tornou a lei conhecida, sendo que a punição relaciona-se à sanção aplicada ao agressor que pratica este tipo de violência. Em seu Art. 20, a lei prevê que em "qualquer fase do inquérito policial ou da instrução criminal, caberá a prisão preventiva do agressor, decretada pelo juiz", e, quando o crime de lesão corporal se configurar em violência doméstica, a sua pena vai de três meses a três anos de detenção, o que consiste em um avanço referente às sanções aplicadas anteriormente a esta lei. Vale destacar as medidas protetivas de urgência à ofendida que a lei prevê, intervindo diretamente no ambiente familiar onde a agredida se encontra. São elas:

Art. 23. Poderá o juiz, quando necessário, sem prejuízo de outras medidas:

I - encaminhar a ofendida e seus dependentes a programa oficial ou comunitário de proteção ou de atendimento;

II - determinar a recondução da ofendida e a de seus dependentes ao respectivo domicílio, após afastamento do agressor;

III - determinar o afastamento da ofendida do lar, sem prejuízo dos direitos relativos a bens, guarda dos filhos e alimentos;

IV - determinar a separação de corpos.

Art. 24. Para a proteção patrimonial dos bens da sociedade conjugal ou daqueles de propriedade particular da mulher, o juiz poderá determinar, liminarmente, as seguintes medidas, entre outras:

I - restituição de bens indevidamente subtraídos pelo agressor à ofendida;

II - proibição temporária para a celebração de atos e contratos de compra, venda e locação de propriedade em comum, salvo expressa autorização judicial;
III - suspensão das procurações conferidas pela ofendida ao agressor;

IV - prestação de caução provisória, mediante depósito judicial, por perdas e danos materiais decorrentes da prática de violência doméstica e familiar contra a ofendida.

Parágrafo único. Deverá o juiz oficiar ao cartório competente para os fins previstos nos incisos II e III deste artigo.

Na segunda pergunta ("Você considera que a Lei Maria da Penha seja uma forma de prevenir a violência contra a mulher?"), 74,1\% das respostas foram afirmativas, o que pode demonstrar que a prevenção entendida pelos participantes da pesquisa está ligada à função preventiva da pena. Assim, afirma Mirabete e Babbrini (2010), que a prevenção especial da pena visa impedir que o agressor pratique novos crimes, intimidando-o e corrigindo-o. Já a prevenção geral da pena pretende intimidar os componentes da sociedade para que não pratiquem crimes.

Deve-se mencionar que, mesmo com o crescimento no número de homicídios contra mulheres, as pessoas creem na eficácia da lei, o que ficou constatado na quarta pergunta do questionário, em que 63,8\% dos participantes confirmaram a crença na eficácia da Lei Maria da Penha. Em 2013, o IPEA (Instituto de Pesquisa Econômica Aplicada) divulgou dados sobre a mortalidade de mulheres no país a partir de pesquisa realizada em agosto daquele ano. Segundo o IPEA, a lei ainda não é suficiente para combaterataxadehomicídioscontraasmulheres, posto que, desde a vigência dela, houve um sutil decréscimo na taxa de mortes, mas que, logo, essa taxa voltou a crescer (GARCIA et al., 2013).

O elevado número de homicídios contra mulheres pode ser entendido por meio de mudanças ocorridas no papel da mulher no contexto social e familiar no século XXI. A independência financeira e a busca das mulheres por níveis de escolaridade mais 
elevados possibilitam a elas obterem autonomia no espaço público e privado, ocasionando transformações nas relações conjugais e familiares. Esse contexto atual pode repercutir na postura masculina, pois, no século passado, o homem era o provedor e chefe da família e a mulher se restringia aos cuidados do marido e dos filhos, sendo submissa a ele. Nesse sentido, Lacerda (2014, p. 13) assinala:

Com o processo de modernização pelo qual vinha passando o país, na década de 1970, ainda no período da ditadura militar, as mulheres passam a incorporar o mercado de trabalho e o sistema educacional e passam a levantar a luta contra valores familiares patriarcais, e hierarquias de gênero.

Além disso, o avanço tecnológico e o maior número de pesquisas relacionadas a esse tema também possibilitam uma maior divulgação dos crimes cometidos contra a mulher no meio público, não se restringindo somente à esfera privada, visto que a violência doméstica contra a mulher, aos poucos, deixa de ser "silenciada" no contexto familiar, conforme ocorria no século XX.

Quanto ao conhecimento sobre como denunciar a violência (quinta pergunta do questionário), $72,4 \%$ do público afirmou conhecer os meios para realizar a denúncia. Seguindo o rol de discussão a respeito do não oferecimento da denúncia por parte das vítimas, questiona-se o porquê de grande parte das agredidas não denunciarem a agressão sofrida. Podemos explicar esse fato pelo medo que a mulher agredida possui do agressor, como comprova também a pesquisa, de março de 2013, realizada pelo DataSenado, juntamente com a Secretaria de Transparência, publicada no site do Senado, sobre a violência contra a mulher, em que se constatou que $74 \%$ das entrevistadas não efetuam a denúncia por medo do agressor, seguido da dependência financeira, que obteve 34\%.
Além disso, existem dificuldades encontradas pela mulher que procura auxílio, em relação aos órgãos responsáveis pelo atendimento. Não somente dificuldades estruturais, como também relacionadas aos profissionais que têm o primeiro contato com aquelas que foram agredidas. Citam-se como exemplos as DEAMs (Delegacias Especializadas no Atendimento a Mulher), que são criadas, porém não são implantadas de fato, muitas vezes, funcionando em condições precárias, além do despreparo e/ou insuficiência de profissionais que atendem as mulheres agredidas e a contratação precária de funcionários temporários (GRUPO..., 2012).

Os resultados obtidos demonstram que o enfrentamento da violência doméstica e familiar contra a mulher ainda requer maior atuação do governo e de setores da sociedade a fim de fornecer meios que retirem a mulher das relações de poder e submissão ao homem. Os investimentos nas estruturas dos órgãos especializados no atendimento à mulher e na equipe de profissionais que os integram devem ser maiores, a fim de atender às necessidades presentes neste tipo de serviço público. As campanhas em nível federal e estadual ainda carecem de investimentos, diante dos problemas enfrentadosnoatendimentoàmulheremsituação de agressão. Nota-se também que as DEAMs constituem um número reduzido se relacionado à extensão territorial que o Brasil possui.

Por fim, a educação e a conscientização de que modelos de conduta e papéis impostos pela sociedade ao longo da história não mais podem ser perpetuados podem ser ferramentas eficazes diante desse problema que atinge milhares de brasileiras no país, sendo este o objetivo geral da presente pesquisa.

\section{Considerações finais}

A violência doméstica praticada contra a 
mulher é uma realidade que atinge a sociedade de diferentes formas e intensidades. Além disso, esse tipo de violência é considerado um problema de saúde pública, bem como um problema social grave que prejudica a integridade física e psicológica da mulher, atingindo sua dignidade. Destaca-se também que a violência doméstica contra mulheres é consequência direta do aspecto histórico-cultural do contexto brasileiro, que ainda apresenta traços machistas e patriarcais, em que, culturalmente, se defende o ditado em que "em briga de marido e mulher ninguém mete a colher".

Contudo, osíndices de violência doméstica contra mulheres não podem ser ignorados, pois ela se torna um círculo vicioso que ocorre no interior dos lares e causa efeitos desastrosos que têm consequências negativas não somente para a mulher, como sujeito de direitos humanos que elaé, por meio das agressões físicas e psicológicas, mas também para a formação dos seus filhos, que convivem com essa desestrutura familiar.

A violência sofrida pela mulher não é de responsabilidade exclusiva do agressor, é resultado da construção histórica e social de estruturas que permitem este tipo de violência. Portanto, é necessário conscientizar a sociedade acerca das consequências da violência doméstica e dos seus efeitos nos aspectos jurídicos e na efetivação dos direitos humanos.

Para proteger a mulher da violência doméstica, conforme foi abordado, é necessário maior engajamento das políticas públicas e de profissionais que atuam na área criminal, além de maior conscientização da sociedade a respeito da discriminação histórica sofrida por elas, a fim de buscar uma sociedade menos violenta e igualitária.

A Constituição Federal, em seu Art. 5ㅜ, assegura que homens e mulheres são iguais em direitos e obrigações, e cabe ao Estado o dever de prestar assistência à família e criar mecanismos para coibir a violência no âmbito de suas relações. Contudo, a ineficiência da justiça brasileira e o tratamento inadequado ofertado às mulheres agredidas antes da incidência da Lei Maria da Penha foram fatores que contribuíram para o lento combate à violência doméstica. Nesse ínterim, é função dos operadores e estudiosos das ciências sociais (incluindo o Direito), por meio da construção do conhecimento científico, agregar informações, de modo a fomentar a pesquisa e, ao mesmo tempo, modificar o contexto social.

Nesse sentido, considerando-se os limites deste estudo, sobretudo por se tratar de uma pesquisa-participante, em que o número de pessoas envolvidas não foi representativo, é necessário que as pesquisas continuem de modo a proporcionar mais visibilidade à violência doméstica contra as mulheres e melhor efetuar uma ação social acerca da problemática do tema - a Lei Maria da Penha -, suas medidas protetivas, as formas de prevenção desse tipo de violência, bem como os procedimentos para efetuar uma denúncia. Espera-se que a exposição oral ofertada aos participantes, assim como as informações contidas nos fôlderes, contribua para a busca de conhecimento a respeito do tema e para divulgação dos benefícios que a lei traz.

\section{Referências}

BANDEIRA, L. M. Violência de gênero: a construção de um campo teórico e de investigação. Revista Sociedade e Estado, Brasília, v. 29, n. 2, p. 449-469, ago. 2014. Disponível em: < http:// www.scielo.br/scielo.php?pid=S0102-69922014000200008\&script=sci_arttext $>$. Acesso em: 11 ago. 2015.

BARROS, S. R. de. Três gerações de direito. 2007. Disponível em: < http://www.srbarros.com.br/ 
pt/tres-geracoes-de-direitos.cont>. Acesso em: 3 ago. 2015.

BASTOS, T. B. Violência doméstica e familiar contra a mulher: análise da Lei Maria da Penha. Porto Alegre: Verbo Jurídico, 2011.

BRANDÃO, C. R.; BORGES, M. C. A pesquisa participante: um momento da educação popular. Revista de Educação Popular, Uberlândia, v. 6, n. 1, p. 51-62, jan./dez. 2007. Disponível em: <http://www.seer.ufu.br/index.php/reveducpop/article/view/19988>. Acesso em: 16 ago. 2015.

BRASIL. Constituição da República Federativa do Brasil. Brasília, 1988. Disponível em: <http:// www.planalto.gov.br/ccivil_03/constituicao/constituicao.htm>. Acesso em: 20 jun. 2015.

. Decreto 52.476/1963. Brasília, DF: Presidência da República, 1963. Convenção sobre os Direitos Políticos da Mulher. Disponível em: <http://www2.camara.leg.br/legin/fed/ decret/1960-1969/decreto-52476-12-setembro-1963-392489-norma-pe.html>: Acesso em: 14 ago. 2015.

. Lei 11.340, de 7 de agosto de 2006. Disponível em: < http://www.planalto.gov.br/ccivil_03/_ ato2004-2006/2006/lei/l11340.htm>. Acesso em: 5 ago. 2015.

. Ministério da Saúde. Saúde, migração, tráfico e violência contra mulheres: o que o SUS precisa saber. Secretaria de Atenção à Saúde. Departamento de Ações Programáticas Estratégicas, Universidade de Brasília. Departamento de Serviço Social. Brasília, 2010. 196p

. Ministério Público Federal. Procuradoria Federal dos Direitos do Cidadão (PFDC). Lei Maria da Penha \& Direitos da Mulher (Cartilha). 2011. Disponível em: <http://www.prrr.mpf.mp.br/ arquivos/pgr_cartilha-maria-da-penha_miolo.pdf>. Acesso em: 11 ago. 2015.

CARVALHO, D. J. A Conquista da cidadania feminina. Revista Saber Acadêmico, São Paulo, n.11, p. 143-153, jun. 2011. Disponível em: < http://www.uniesp.edu.br/revista/revista11/pdf/artigos/12. pdf $>$. Acesso em: 11 ago. 2015.

CORREAA, R. C. (Org.). O enfrentamento à violência doméstica e familiar contra a mulher: uma construção coletiva. 2011. Disponível em: <http://www.mppr.mp.br/arquivos/File/ cartilhaViolenciaContraMulherWeb.pdf>. Acesso em: 10 ago. 2015.

DATASENADO. Violência doméstica e familiar contra a mulher. 2013. Disponível em: < http:// www.senado.gov.br/senado/datasenado/pdf/datasenado/DataSenado-Pesquisa-Violencia_ Domestica_contra_a_Mulher_2013.pdf>. Acesso em: 22 jun. 2015

DEFENSORIA PÚBLICA DE SERGIPE. Índice de violência contra a mulher preocupa a Defensoria Pública. 2014. Disponível em: <http://www.defensoria.se.gov.br/?p=5878>. Acesso em: 19 jun. 2015.

DEFESA DA MULHER. ONGs que trabalham com violência contra a mulher no Brasil. Disponível em: <http://wjdwdefesadamulher.blogspot.com.br/2011/02/ongs-que-trabalham-com-violenciacontra.html>. Acesso em: 15 ago. 2015.

DIAS, M. B. A impunidade dos delitos domésticos. 2011. Disponível em: <http://www. 
advocaciadamulher.com.br/meus-direitos/artigos/68-direito-de-familia/220-a-impunidade-dosdelitos-domesticos.html>. Acesso em: 12 ago. 2015.

DIAS, M. B. A Lei Maria da Penha na justiça: a efetividade da Lei 11.340/2006. 3. ed. São Paulo: Revista dos Tribunais, 2012.

GARCIA, L. P. et al. Violência contra a mulher: feminicídios no Brasil. 2013. Disponível em: <http://www.ipea.gov.br/portal/images/stories/PDFs/130925_sum_estudo_feminicidio_leilagarcia. pdf $>$. Acesso em: 22 jun. 2015.

GIL, A. C. Como elaborar projetos de pesquisa. São Paulo: Atlas, 2002.

GOULART, L. H. S. QUIRINO, M. A. G. D. Sociedade conjugal: interpretação do artigo 977 do código civil. Revista Eletrônica de Direito, Belo Horizonte, 20 ed., jun. 2013. Disponível em: <http://npa.newtonpaiva.br/direito/?p=1170>. Acesso em: 3 ago. 2015.

GRUPO DE TRABALHO DA REDE DE ATENÇÃO ÀS MULHERES EM SITUAÇÃO DE VIOLÊNCIA. A Bahia e a violência contra Mulheres (Dossiê). jul. 2012. Disponível em: $<$ http://www.senado. gov.br/comissoes/documentos/SSCEPI/DOC\%20VCM\%20216\%20PRINCIPAL.pdf>. Acesso em: 13 ago. 2015

INSTITUTO BRASILEIRO DE GEOGRAFIA E ESTATÍSTICA (IBGE). Síntese de indicadores sociais: uma análise das condições de vida da população brasileira. 2009. Disponível em: <http://www.ibge. gov.br/home/estatistica/populacao/condicaodevida/indicadoresminimos/sinteseindicsociais2010/ SIS_2010.pdf>. Acesso em: 15 mai. 2015.

LACERDA, M. M. A naturalização da violência contra mulher como uma construção sóciohistórica passível de desconstrução. 2014. 35 f. Trabalho de Conclusão de Curso (Graduação em Serviço Social) - Universidade Estadual da Paraíba, Centro de Ciências Sociais Aplicadas. Paraíba, 2014. Disponível em: <http://dspace.bc.uepb.edu.br:8080/jspui/bitstream/123456789/5273/1/ PDF\%20-\%20Martina\%20Mendes\%20de\%20Lacerda.pdf>. Acesso em: 16 ago. 2015.

ORGANIZAÇÃO MUNDIAL DE SAÚDE (ONU). Dia Internacional para a eliminação da violência contra a mulher. 2011. Disponível em: <http://www.onu.org.br/dia-internacional-para-aeliminacao-da-violencia-contra-a-mulher-2011>. Acesso em: 16 ago. 2015.

Sobre a ONU mulheres. 2015. Disponível em <http://www.onumulheres.org.br/onumulheres/sobre-a-onu-mulheres/>. Acesso em: 15 jun. 2015.

MIRABETE, J. F.; FABBRINI, R. N. Manual de Direito Penal. 27 ed. São Paulo: Atlas, 2010.

MORAES, A. Direito constitucional. São Paulo: Atlas, 2010.

MOREIRA, V.; BORIS, G. D. J. B.; VENÂNCIO, N. O estigma da violência sofrida por mulheres na relação com seus parceiros íntimos. Revista Psicologia e Sociedade, Florianópolis, v. 23, n. 2, p. 398-406, ago. 2011. Disponível em: <http://www.scielo.br/scielo.php?pid=S0102$71822011000200021 \&$ script=sci_arttext $>$. Acesso em: 11 ago. 2015. 
OLIVEIRA, E. R. Violência doméstica e familiar contra a mulher: um cenário de subjugação do gênero feminino. Revista do Laboratório de Estudos da Violência da UNESP, Marília, 9. ed., maio. 2012. Disponível em: <http://www2.marilia.unesp.br/revistas/index.php/levs/issue/view/187> . Acesso em: 10 ago. 2015.

PASINATO, W. Lei Maria da Penha: novas abordagens sobre velhas propostas - onde avançamos? Revista Civitas, Porto Alegre, v. 10, n. 2, p. 216-232, maio-ago. 2010. Disponível em: <http:// revistaseletronicas.pucrs.br/ojs/index.php/civitas/issue/view/469>. Acesso em: 18 jun. 2015.

PIOVESAN, F. A. Proteção internacional dos direitos humanos das mulheres. Revista da Escola da Magistratura do Estado do Rio de Janeiro, Rio de Janeiro, v. 15, n. 57, p. 70-89, jan.-mar. 2012. Disponível em: <http://www.emerj.tjrj.jus.br/revistaemerj_online/edicoes/revista57/revista57_70. pdf>. Acesso em: 10 ago. 2015.

PORTAL BRASIL. Cinco mulheres são agredidas a cada dois minutos no Brasil. 2014. Disponível em: $\quad$ http://www.brasil.gov.br/governo/2011/02/cinco-mulheres-sao-agredidas-a-cada-dois-minutosno-brasil>. Acesso em: 3 ago. 2015.

RIBEIRO, C. G. COUTINHO, M. L. L. Representações sociais de mulheres vítimas de violência doméstica na cidade de João Pessoa-PB. Revista Psicologia e Saúde, Campo Grande, v. 3, n. 1, p. 52-59, jan.-jun. 2011. Disponível em: < http://www.gpec.ucdb.br/pssa/index.php/pssa/article/ view/81/142>. Acesso em: 19 jul. 2015.

STELKO-PEREIRA, A. C.; WILLIAMS, L. C. A. Sobre o conceito de violência: distinções necessárias. In: WILLIAMS, L.C.A.; MAIA, J.M.D.; RIOS, K.S.A. (Org.). Aspectos psicológicos da violência: pesquisa e intervenção cognitivo-comportamental. Santo André: ESETec, 2010. p. 41-66.

Submetido em 2 de julho de 2015.

Aprovado em 27 de setembro de 2015. 